\title{
The Ninth International Leprosy Congress
}

\section{Report on the Week}

Many readers of Leprosy Review were among the registered participants or day visitors at the Congress. For those who were not privileged to be present, the following report may provide at second-hand an indication of its importance and significance. When close on 500 people interested in leprosy converge from over 70 countries to one centre, and there listen to 235 papers delivered in 4 languages in 17 working sessions, no-one can predict the immediate and remote results.

Her Majesty Queen Elizabeth II, whose personal interest in leprosy is well known, sent a special message to the Congress, of which she graciously consented to be Patron. The VicePatrons represented diverse official, professional, local and international bodies concerned in some way with leprosy, together with the two main voluntary agencies in Britain.

Dr. Robert G. Cochrane, President of the International Leprosy Association, was President of the Congress. The Organising Committee consisted of Drs. S. G. Browne, R. J. W. Rees, D. S. Ridley and (until his untimely decease) J. Ross Innes.

\section{WORKING PARTIES}

Working parties were held both before and after the Congress. Some were organised by the World Health Organization (on the standardisation of lepromin; $M$. leprae; leprosy therapy; methodology in drug trials in leprosy), by the Leonard Wood Memorial (on cultivation of $M$. leprae), by Messrs. G. R. Geigy (B663 (Lampren) in the treatment of leprosy and leprosy reaction), and by the Congress (on classification; and thalidomide therapy in leprosy reactions).

\section{SCIENTIEIC PROGRAMME}

All meetings were held in the fine new buildings of the Mechanical Engineering Department of the Imperial College of Science and Technology,
South Kensington, by kind permission of the Principal, Professor E. B. Chain.

Simultaneous translation was provided for all the main scientific sessions in English, French, Portuguese and Spanish. In addition, facilities were offered for translation into and from Japanese.

In accordance with modern practice in Congresses sponsored by scientific organisations, the sessions were in the nature of a series of symposia at which specific matters were considered. The Panels, which were a feature of former Congresses, found no place in London, 1968. Consequently, key leprosy workers had time and opportunity to attend the sessions, and play their full part in discussions, without being diverted by the claims of panel discussions and the compilation of voluminous reports that had to meet an inexorable deadline.

\section{EXHIBITION}

Microbiological research, osteological material from medieval churchyards " in Denmark, sophisticated microscopes, leprosy periodicals, voluntary agencies-all had their activities displayed in the Exhibition Hall.

\section{SOCIAL PROGRAMME}

A very full social programme had been organised, with the express object of providing participants and their wives with opportunity for meeting and discussing.

In addition to the Welcoming Reception sponsored by the International Leprosy Association, Receptions were offered by the National Fund for Research into Crippling Diseases (at Apothecaries' Hall), by Sir Cyril and Lady Black (at the House of Commons), by The Leprosy Mission, the Ministers of Health and Overseas Development (at Lancaster House), and by the Greater London Council.

The Congress Banquet was held at the Savoy 
Hotel, at which the special guest, Sir Max Rosenheim (President of the Royal College of Physicians of London), gave a most fascinating speech.

The Ladies' Committee, under the Chairmanship of Mrs. Stanley Browne, had organised a full programme of visits to places of interest for Associate Members of the Congress-to Luton Hoo, around the City of London, to Windsor, and by boat to Greenwich. For the most part, the weather was kind, notwithstanding the cloudbursts and floodings that immediately preceded the week of the Congress.

The Congress was officially inaugurated on Monday, 16 September, by the Rt. Hon. Kenneth Robinson, M.P., Minister of Health, whose speech set the tone for the week's activities. The Minister welcomed the participants, and assured them of the interest that would be taken by the Government in their deliberations. He referred to the valuable contributions made by British voluntary organisations and British scientists to the continuing fight against leprosy, and mentioned that Great Britain today had its own leprosy problem, by no means negligible. He called for more co-operation in leprosy research; he looked to the medical scientists to make some definite pronouncement on the value of BCG vaccination in preventing leprosy; and he called on all present 'never to neglect the intimate and real social and psychological problems of the sufferer and his family'. He continued, 'In your very commendable scientific investigations, you will never, I am confident, allow your interest in the cellular reaction in the mouse to cloud your concern for the human plight of the man.'

A message was read from Her Majesty the Queen, and greetings and good wishes were voiced by Alderman Sir Harold Gillett on behalf of the Lord Mayor of London and the City Corporation; Dr. L. M. Bechelli, for Dr. M. G. Candau, Director General of the World Health Organization; Mr. H. C. Edwards, Vice-President of the Royal College of Surgeons of England; Dr. S. G. Browne, on behalf of Sir Max Rosenheim, President of the Royal College of Physicians of London; Dr. B. B. Waddy, for the President of the Royal Society of Tropical Medicine and Hygiene. The Parliamentary Secretary to the Minister of Overseas Development (Mr. A. E. Oram, M.P.), and the ViceChairman of the Greater London Council (Mr. G. W. Aplin) were unfortunately prevented by flooded roads from attending, but managed to telephone messages of greeting.

\section{Some Highlights of the Week's Work}

The following report is taken, with the Editor's permission, from the special Congress supplement of the International Journal of Leprosy (Vol. 36, No. 4). This permission is gratefully acknowledged.

In this review, I select from the Chairman's Reports of each of the scientific sessions some of the features that they themselves would wish to emphasise.

First, Session II: Epidemiology, including Genetics (Chairman: Dr. Carl Taylor).

The dominant features of the epidemiology of leprosy are a general dissatisfaction with traditional approaches and a hunt for new methods. The search for genetic markers having an association with specific types of leprosy has so far furnished only suggestive leads, and no clear indication of their significance. Other methods of genetic study as are now available give as yet no indication of their potential value.

The epidemiological significance of the lepromin test continues to be minimal, and the evidence that large proportions of positive conversions are unrelated to leprosy infection, but possibly associated with non-pathological mycobacterial infections, has been increasingly demonstrated. The Karimui research project team has proved the value of intensive and continuing observations on population groups sufficiently small, and sufficiently isolated, to give consistent data; incidentally, more evidence of spontaneous healing, self-regressing leprosy lesions has come to light. More such clinical and field studies are needed.

Ninth International Leprosy Congress

189 
We have been reminded of the value of anthropological research in leprosy. It may be that such factors as marriage patterns will provide suggestive leads concerning infection, and emphasise the importance of repeated close or skin-to-skin contacts with index cases disseminating viable mycobacteria from skin and nasal mucosa.

A timely reminder came from Bengal, that many healthy people not in contact with open leprosy patients, may harbour mycobacteria in skin and deeper tissues. So far, there is no laboratory confirmation that these organisms are indeed Mycolacterium leprae. This work underlines our lack of appropriate cultural media, perhaps including some specific adjuvants as postulated by Hanks, that will permit the cultivation and identification of $M$. leprae amongst all mycobacterial contaminants of the skin surface, and the deeper tissues. Japanese workers have demonstrated that acid-fast bacilli are found in normal human skin in subjects having no possible contact with leprosy. More intensive investigation and carefully planned surveys, with well-documented records and adequate statistical control, must be organised in an attempt to answer the simple, but extremely profound, questions. How is leprosy spread? Is there an extra-human reservoir? Where does $M$. leprae live? And how does this fastidious organism, with its extremely particularised growth requirements, manage to survive and to multiply? These are questions that still await elucidation. The simple questions, the most profound, are frequently the most difficult to answer.

Dr. C. C. Shepard's Session (IV) was one of the most important of the Congress. More new work, and more new significant work was reported here than elsewhere. Details of accurate technical estimations of limited multiplication of $M$. leprae in the mouse foot-pad, were supplemented by Rees' work on the production of widespread bacilliferous granulomata in the thymectomized and irradiated mouse.

The observation that muscle as well as nerve tissue provides a suitable nidus for mycobacterial multiplication has been further investigated by several workers.

The fundamental immunological differences in the human host, differences that are clinically exteriorised in the polar types of leprosy, may be associated with physiological disparity in certain tissue and blood cells. Anti-lymphocytic globulin is reported to enhance the susceptibility of mice to mycobacterial challenge.

The well-known parasitisation of human reticulo-endothelial cells in patients suffering from lepromatous leprosy, has stimulated further work in cell culture and attempts to induce cells from patients already exhibiting failure to lyse and clear mycobacteria, to harbour $M$. leprae. Human skin fibroblasts appear to possess the requisite biochemical and immunological properties to permit such multiplication.

Various adjuvant factors are being investigated in the hope that the ideal substance may one day be found.

'All is not gold that glitters', and mycobacterial strains labelled $M$. leprae in the past are now found to have been incorrectly identified; they mostly belong to the fast-growing mycobacteria differentiable from $M$. le prae by recently developed and more sophisticated laboratory techniques.

Filterable forms of mycobacteria may exist. We need to know more about this possibility.

Morphology and viability, pleomorphism of mycobacteria, L-forms, phenoloxidases and other adjuvant or inhibitory enzymes-all were discussed and notable contributions came from laboratory workers from many countries.

Dr. Weddell's Session (VI) considered the pathology of leprosy with especial reference to its neurological aspects. The most important findings reported were the ultrastructural changes in nerves as revealed by electronmicroscopy. There is a growing awareness that immunologically significant changes occur as a response in tissue hypersensitised in some way by mycobacteria or by certain biochemical moieties of their breakdown products. It is not yet possible to distinguish the basis for the extremely varied response at the cellular and at the ultramicroscopical level in leprosy. Is it 
pressure? Is it oedema? Is it cellular infiltration? Is it something else? And, whatever it is, what is the fundamental, the ultimate pathology? This may seem to some to be an academic question, but it is of extreme significance to the patient who has leprosy and who is liable to rapid and progressive and irreversible damage to his peripheral nerves with the orthopaedic consequences-paralyses, pareses, anaesthesiae, etc.

Then, in Dr. Hank's Session (VIII), clear evidence was presented that the anergy of lepromatous leprosy was due in part to a subnormal response of leucocytes to physiological stimuli, and to antigens that may be totally unrelated to $M$. leprae. These responses are suppressed by factors occurring in lepromatous serum. The investigations by Dr. Bechelli and others on the Mitsuda reactivity in a noncontact population demonstrated the usefulness of a lepromin containing only 20 million organisms per millilitre, not the 600 million that has hitherto been regarded as the optimum for field work. These results suggested that the lepromin reaction might become positive after the 28th or even the 35th day. This work had been anticipated in São Paulo and elsewhere.

Laboratory investigations disclose further refinements of method for analysing the serological alterations in leprosy and the crossreactions between $M$. leprae and other relatednearly or distantly related-mycobacteria.

Dr. D'Arcy Hart's Session (X) provided extremely useful data for the continuing debate on the value of $B C G$ vaccination in leprosy.

If $\mathrm{BCG}$ does really enhance innate potential resistance to challenge by $M$. leprae, or induce such resistance where it is non-existent, and if it will do this in children exposed intrafamilially to such challenge, then this would be the most important single advance in leprosy prophylaxis. If it is true, everybody should know and voluntary organisations and governments should be devoting a high proportion of their resources to controlling leprosy by these means. But wherein lies the truth?-Uganda$80 \%$; Papua and New Guinea-56\%; Burma $-0 \%$.
Many millions of people are exposed to $M$. leprae, and many will develop leprosy this year, next year and the year after. It is quite impossible to treat adequately and to render non-contagious all patients with lepromatous leprosy in the world within the foreseeable future. If BCG should show the way to prevent leprosy, we beg the epidemiologists to tell us; and meanwhile encourage them to pursue their investigations. In some ways, therefore, this was a disappointing session, not because of the quality of the papers but because of the complexity and the contradictions of the conclusions. It remains for WHO to stimulate further trials, with impeccable statistical control, and severe and critical evaluation; fieldwork, standards and methods must be systemised and correlated, for weighty edifices cannot be built on the collected mass of unreliable primary data. The king-pin in these large-scale investigations is the man working in the field, and not those who, by means of sophisticated instruments, summarise his observations.

It now appears to be established that dapsone, regularly administered to children exposed to leprosy, will protect a high proportion of them against the development of overt lesions.

Dr. Ribley's Session (XII) on the immunological aspects of reaction provided much light and no little heat. Four types of reaction can be identified, which differ in their immunological and prognostic significance, although they have a number of important points in common. Research on their pathogenesis is still in the stage of collecting data. Some promising approaches have produced negative or even inconsistent and contradictory results.

The concept of leprosy as an infection, in which immunity is essentially cell-mediated by lymphocytes, and in which anergy is associated with suppression of lymphocyte production, sheds light on several problems. Reactions associated with an increase of immunity and a movement towards the borderline form of leprosy, may be precipitated in experimental infections in thymectomised mice by injection of normal lymphoid cells. These results represent a distinct advance and, coupled with the work

Ninth International Leprosy Congress

191 
of Rees and Gaugas at Mill Hill, give us some extremely useful pointers to future research in this aspect of leprosy. It is a well-known fact that erythema nodosum leprosum is associated with an increase of complement; immunoglobulins are also increased, and a number of auto-antibodies are sometimes present; but these are no greater in amount-and sometimes are actually less-than in patients with nonreacting lepromatous leprosy. Here again, a problem is presented, and questions are asked that may seem facile to pose but are extremely difficult in practice to answer. The fluorescent antibody techniques (in which many of us pinned a certain amount of faith) are giving inconstant results. Erythema nodosum leprosum has a number of parallels with serum sickness, which is due to circulating antigen-antibody complexes.

Dr. Azulay (Session XIV) was concerned with the clinical and practical aspects of leprosy reaction and the therapy of such reaction. The 2 main points brought out in this session were the remarkable progress in the therapy of leprosy reaction, the first being thalidomide, and the second, the Riminophenazine derivative, the aposafranin, B663. With recent memory of its teratogenic and neurotoxic properties, and the knowledge that the legal process against its German manufacturers is now taking place, some practitioners are wary of thalidomide. The drug seems to have a specific anti-inflammatory effect in leprosy reaction and, as Professor Sagher's working party suggests, it is indicated precisely in acutely reacting lepromatous leprosy. The dose recommended is between 100 and $400 \mathrm{mgm}$. per day; after remission of the acute phase, it may be decreased. The drug has no effect on the disease itself; in fact, its use may be followed by some increase in the leprosy lesions. Some side-effects have been noted, mainly oedema of the extremities and some dizziness and pruritis, but in the main these are not serious. Homologues, derivatives and breakdown products of this drug are being investigated for their possible activity in leprareaction. We await with interest further - researches along these lines.
B663 is reported to have a definite antiinflammatory action in the acute exacerbation of lepromatous leprosy. It is active both in the acute exacerbation and also in leprosy itself; in the future it may find its sphere of usefulness in patients with established reaction. It must be given in adequate doses, just as the dose of cortico-steroids are given for their inflammatorysuppressive activity, must vary. It may also be given to patients with severe lepromatous leprosy, especially to those who appear to be prone to develop acute exacerbation. This may prove to be a wide field for this drug; since it may usefully be presented in those situations where it is economically feasible and advisable to give such a drug, e.g., because of the consequences of acute, persistent and prolonged acute exacerbation in lepromatous leprosy in a wageearner, the head of a family, who has lepromatous leprosy but who wants to be allowed to continue working.

In Dr. S. R. M. Bushby's Session (XVI) the most valuable advance in the field of experimental chemotherapy since the last Congress is the exploitation of the observation by Shepard that $M$. le prae multiplies locally when injected into the footpads of mice. This discovery has produced an experimental model that will permit the determination of the sensitivity of $M$. leprae to drugs suspected of having an anti-leprotic activity. Using this model, Dr. Rees and his colleagues (to whom we now pay tribute) have confirmed that the bacilli from patients who relapse during dapsone therapy are less sensitive to the drug than are those from untreated patients. Truly resistant bacilli, in certain cases, may show cross-resistance with the sulphonamides. Although fully sensitive strains are inhibited by serum levels as low as 0.02 micrograms of DDS per millilitre (which corresponds to a daily dose of 0.1 milligramme for the adult weight $50 \mathrm{~kg}$.), the need for maintaining in the human subject relatively high concentrations is apparent, when it is realised that mycobacteria develop resistance to sulphones by a stepwise process (as has been reported from Baltimore) and that the degree of resistance to the strains from relapsing patients varies within wide limits.

\section{Leprosy Review}


By this method, DDS has been shown to be bactericidal, and there is a distinct difference between bacteriostasis and bactericidal activity. We are grateful to Shepard for developing the kinetic method of demonstrating this difference. It may be that the minimal inhibitory dose may have to be increased many times in the human patient if the emergence of resistant strains is to be forestalled.

Dr. M. F. R. Waters' Session (XVII) concentrated particularly on B663, low-dose dapsone, and long-acting sulphonamides-drugs that together seem to provide some prospect of hope for patients with lepromatous leprosy in rural campaigns who are able to receive a visit from a doctor but infrequently.

The long-acting sulphone, DADDS, may, when given as a single intramuscular injection once every 3 months, produce and maintain a therapeutic blood level of active drug.

The pharmacology and toxicology of B663 were considered at some length; the antileprosy activity of the drug is apparently of the same order as that of dapsone. It has been found invaluable in cases of proven dapsone-resistance. The main disadvantage from its use is a ruddy pigmentation of the skin, followed by darkening: these changes of colour tend to disappear slowly when the drug is no longer given.

Dapsone is reported to be active in extremely low doses, such as 5 or $10 \mathrm{mgm}$. a week, which, however, are theoretically still well above the minimal inhibitory dose. With these low doses, a vigilant watch must be kept for the emergence of drug-resistant strains.

In Argentina it is found that patients with lepromatous leprosy respond more rapidly to sulphonamides than to dapsone, while in Africa some workers have found the long-acting sulphonamides to be particularly valuable in tuberculoid leprosy.

Numerous long-acting sulphonamides are now being synthesised, and it is not outside the bounds of possibility that one day a new compound will be developed that is very much better than the existing long-acting and depot sulphonamides and which can be used in mass treatment campaigns without grave risk of complications and toxic effects. Meanwhile, it is well to remember that these drugs have certain inconveniences and disadvantages, and that they are expensive.

A plea for regular treatment of patients with lepromatous leprosy was reinforced by the report that bacterial negativity could be achieved more rapidly by regular treatment. However, even when approved dose-schedules were followed, the relapse rate in a rural leprosy control scheme concerned mainly with patients with non-lepromatous leprosy, was found to be nearly $5 \%$.

Some work was reported on the newer drugs; ethambutol is effective for a short time; rifamycin was used in a small uncontrolled series with apparently good results. These 2 drugs may open the door to new advances in leprosy therapy, particularly the derivatives and related antibiotics of the latter, some of which show definite and high myco-bactericidal activity.

Several speakers at this session emphasised the need for carefully controlled trials of drugs with suspected anti-leprosy activity, and for comparison with standard dapsone therapy.

In the concurrent sessions, extremely important and useful papers were read, and fruitful discussions followed.

Session III (Mr. HobBs). The ophthalmological aspects of leprosy provoked lively debate. It was reported that many clinicians and many laboratory workers were quite unaware of the dimensions of eye complications. The pro. portion of patients with lepromatous leprosy who have ocular complications at some time or other in the course of their disease is extremely high. Rarely, ophthalmological manifestations may be the presenting sign of the disease, heralding very serious lepromatous disease, before there are any apparent skin changes. All clinicians should familiarise themselves with the slit lamp, possibly a small portable instrument that can be used by the amateur in the tropical jungles. Every leprologist may not be an ophthalmological specialist, but all clinicians should know how to use a slit lamp. Doctors 
were urged to spread knowledge about the ophthalmological complications of leprosy not only to fellow doctors but especially to paramedical workers and nurses. These latter, in fact, are treating over nine-tenths of the patients under leprosy control today, and they should be aware of the early signs of ocular involvement. The early recognition of signs of ocular disorder, very often in the pre-symptomatic stage, is perfectly practicable. For the more highly sophisticated, the budding ophthalmic surgeons, one speaker emphasised that cataract-extraction or keratoplasty, in the past considered unsafe and not worth the risk, can be quite feasible, and is effective in expert hands.

In Professor 'T. N. Jagadisan's Session (V) emphasis was placed on physiotherapy and its role in the prevention of deformity. Many countries cannot afford a physiotherapy service, but they can afford perhaps one physiotherapist, who can train others. I would beg of you to co-operate with The Leprosy Mission and LEPRA and with certain governments that can afford physiotherapists; invite them, and give them the opportunity of teaching others, not to produce a highly sophisticated (and admittedly rather expensive) reconstructive surgery unit, but encourage them to disseminate knowledge of prevention-prevention of deformity, prevention of ulceration of the anaesthetic feet; prevention is better, and cheaper, than cure. Conservative measures will prevent ulceration of the anaesthetic extremities, and permanent dropping of the feet. Prevention will ensure that the very acutely inflamed nerve will be rested until the phase of oedema is over.

When secondary deformity is established, recourse must be had wherever possible to the surgeons; they provide reconstructive surgery that helps the patient who caught leprosy too long ago, and who has suffered since.

It is not only the orthopaedic, the reconstructive surgeons, who must be enlisted in this task-as they do their Cockett's operation on the nose, and post-nasal inlays, and the restbut also the 'jobbing surgeon' who is conf ronted by row upon row of people with ulcerated and dropped feet, with sagging faces, and with paralysed ulnar nerves. Jobbing surgeons can do much, provided they do not spend time and energy attempting to perfect their surgery while allowing thousands of patients in the villages to develop deformities. When secondary deformity has occurred, however, there is a real need for the co-operation of the prosthetist, the footwear maker and the occupational therapist.

As far as physiotherapy is concerned, of course, the selection and preparation of patients for tendon-transfer surgery is all-important. In order to obtain the maximal post-operative functional capacity, with good appearance, the active co-operation of the patient with the physiotherapist, and the surgeon, and the prosthetist is essential. These skills must be shared with the ordinary poly-competent paramedical worker, who is responsible for most of the leprosy treatment in the world today. It is he who mediates our skills and educates the patient in the protection of anaesthetic extremities, and it is he who helps the patient back to life and health again.

Dr. Molesworth's Session (VII) had to confess that successful leprosy control is achieved but rarely. This failure is in part a reflection on us, and on governments for not making more money and more people available; but, in any case, much more should be done. The integration of leprosy services with existing services and the training of paramedical workers were repeatedly stressed.

The speakers took note particularly of the time consumed and the proportion of finance involved in institutional care. Some countries can afford it; most cannot. And where intensive campaigns are in progress, a great increase in the number of registered cases occurs. Leprosy is always far more prevalent than is realised on initial surveys.

The surgeons had most stimulating meetings, with BRAND and Antia contributing magnificently through their Sessions (IX AND XI) to the application of reconstructive surgery to the patients who caught leprosy too long ago, or who were inadequately treated. They emphasised the value of visits from one country to another, 
from one surgical group to another; they considered various technical matters such as the excision of metatarsal heads for persistent ulceration of the forefoot.

At the close of Session IX, the place of surgery in leprosy control programmes was considered. In New Guinea it was demonstrated how a single surgeon, working out from a base hospital, can carry out 'surgical camps' in a large number of small general hospitals. In each centre, there is a trained auxiliary who carries on before and after the visit of the surgeon. Therefore, postoperative and pre-operative treatment can be given, and the evidential value of these expert visits has to be seen to be believed. This system has resulted in general hospitals becoming willing to co-operate, first in the rehabilitation programme and later in leprosy control. This is, in other words, a practical demonstration, through the surgeons, of what should be done and what can be done. The surgeon has thus built a bridge between the highly-specialised orthopaedic and reconstructive surgery unit and the leprosy team and the ordinary patient in the villages scattered in the remote mountain valleys of Papua and New Guinea.

In Dr. Antia's Session (XI), there was some excellent discussion on certain surgical aspects of nerve-pain and the prevention of paralysis, but the greatest interest was evoked by reports on the pathology of nerve damage in leprosynothing new, but all very stimulating. Not only nerves, but smooth muscle cells are now seen to be microscopical sites of predilection for M. leprae.

The psychological aspects of leprosy provided a varied programme in SEssion XIII (Chairman: Dr. Oliver W. Hasselblad). The main conclusion was that there is much ignoranceignorance among doctors and paramedical workers, among administrators, among leprosy patients themselves and the community. Much more must be done to investigate psychological attitudes of the individual patient and of the community in which he lives, so that, eventually, the stigma of leprosy will disappear and leprosy will be treated in the patient's inner mind, as well as in the community, as a disease, like other diseases. Results from Bombay, as well as from the United States of America, stressed these findings. Confidentiality should be preserved at all points and secrecy must be maintained, but a tremendous amount needs to be done to help the leprosy patient from becoming dependent on the community and isolated from that community.

In Session XV (Mrs. Weaver) several interesting papers were presented that covered familiar ground and emphasised old truths in new ways. While some countries are able to report a certain progress in leprosy sociology and the acceptance by society of the fact that leprosy exists, and the associated and often equally unpalatable fact that those who suffer from leprosy are indeed human beings and should be treated as such, elsewhere the stigma dies hard and the unwarranted aura of superstition and folk-lore shows little sign of dispersing.

The urge to social rehabilitation of ten depends on the informed enthusiasm of the individualin government service or in a voluntary organisation. Planning is essential, but impersonal planning may defeat its own end; much depends on the drive and personal sympathy of those in charge.

The knowledge that social services are available, that discrimination is officially frowned upon, that employment for the patient and support for his family are assured, may do much to augment and strengthen any anti-leprosy campaign. It is in the relatively wealthy countries, and in urban and sophisticated communities, that these welfare and social services are not only working but are seen to be most effective. Nevertheless, in the developing countries, with their larger and less tractab'e leprosy problem, rural rather than urban, $\mathrm{s}^{-} \mathrm{ch}$ schemes for the rehabilitation of the les rosy patient are no less essential.

Much discussion was aroused over the proposal to abolish the word 'leprosy', and to replace it by an eponymous or neutral scientific descriptive term, but some contributors were of opinion that the disease rather than the name

Ninth International Leprosy Congress

195 
of the disease needed rehabilitation, and that all efforts should be bent towards education of the public, the medical profession (including medical students) and politicians in the true nature, importance and curability of this widespread and crippling disease.

Dr. Davey's Session (XVIII) on 'Cooperation and Priorities' attempted to translate into the humdrum world of practical politics the scientific advances now available, and to relate the leprosy problem to the human and material resources at our disposal. The essential intractability of leprosy as a disease of the physical nature of man-with its non-material overtones-renders any piecemeal attack abortive and ineffective. We are dealing with persons, living in a social environment and conditioned by many and diverse factors. If existing knowledge could be applied on a world scale, even though many of the answers to the problems leprosy poses still elude us, then the slow spread of leprosy could be halted. More emphasis should be placed on well-planned leprosy control schemes, integrated wherever possible with general health measures. Unless and until the huge reservoir of patients with 'open' leprosy is tackled realistically and co-operatively, then the endemic will continue to smoulder.

The session ended with a plea for cooperation-between governments and voluntary agencies, between national and international agencies, between the more affluent and the poorer countries of the world, between the research scientist and the field worker. Cooperation is also necessary between those engaged in all aspects of leprosy, and those coming into leprosy from other branches of science. Given these priorities, and this degree of co-operation, leprosy could be 'controlled in our generation and eradicated in the next'. 